\title{
María Elena: el fin de una experiencia urbana. Un estudio de caso en el desierto de Atacama, Chile*
}

\author{
JUAN CARLOS RODRÍGUEZ TORRENT** Y PABLO MIRANDA BOWN*** \\ **Antropólogo, profesor e investigador Escuela de Diseńo, Facultad de Arquitectura, Universidad de Valparaíso. \\ ***Licenciado en Antropología con mención en Arqueología, Magíster en Psicoanálisis, profesor e investigador \\ Escuela de Arte, Pontificia Universidad Católica de Chile.
}

\begin{abstract}
In this paper we look into the relationship between the nitrate town of Maria Elena (in Region II) - designed on utopian principals as a private project - and the changing labor relations between the SQM Company and the workers as a result of the predominance of a new accumulation model guided by competitiveness, quality production and globalization. The town was created so that men and women could establish their livelihoods in the Atacama Desert, with guarantees and infrastructure based on a full employment policy. This was in order to anchor the population in this inhospitable environment, to meet production objectives and to strengthen a coherent and cohesive identity. New strategic decisions led to this model being replaced by one based on labour flexibilization, deleting its original intention and collective interest to give way to a mining camp.
\end{abstract}

KEYWORDS: town, cultural change, full employment, labor flexibilization.

RESUMEN En el presente trabajo se plantea la relación entre la ciudad salitrera de María Elena (II Región), diseñada de acuerdo a propuestas utópicas en un territorio privado, y el cambio de las relaciones laborales entre la Compañía SQM y los trabajadores a partir del predominio de un nuevo modelo de acumulación cuyos ejes están dados por la competitividad, la producción de calidad y la globalización. La ciudad fue creada para que hombres y mujeres construyeran sus proyectos de vida en medio del Desierto de Atacama, ofreciéndoles todas las garantías y la infraestructura para que ello fuese así en los marcos de una política de pleno empleo, de modo de contener a la población en un medio inhóspito, cumplir los objetivos productivos y fortalecer una identidad coherente y cohesionada, lo que a partir de nuevas decisiones estratégicas es substituido por un modelo de flexibilidad laboral, lo que anula su definición primigenia y el interés colectivo para comenzar a dar paso a un campamento minero.

PALABRAS CLAVE: ciudad, cambio cultural, pleno empleo, flexibilización laboral.

\footnotetext{
Proyecto Fondecyt 1060092, "María Elena, cambio y reestructuración cultural. Una cartografía antropológica de sus marcadores".

Recibido el 30 de noviembre de 2007, aprobado el 16 de enero de 2009.

Correspondencia: Juan Carlos Rodríguez, Exequiel Fernández Nº 90, Depto. 1309, Nuuñoa. E-mail: memoriasur@ gmail.com.
} 


\section{La construcción de la identidad a partir de un proyecto utópico de ocupación territorial}

En este trabajo, que es parte de un importante registro desarrollado a partir de 1998, el interés se centra en la identificación y tratamiento de algunas variables e indicadores del proceso de cambio urbano de María Elena, última ciudad del salitre, a partir de la experiencia y contrapuntos entre el antes y el ahora referidos por sus habitantes. Sintetiza y analiza el paso desde una ciudad del salitre a un campamento minero, tesis que ha sido configurada metodológicamente en el trabajo de campo por preguntas generales que han guiado la investigación en torno al modo de vida de sus habitantes y su relación con la infraestructura, y que han abierto otras fronteras más íntimas de la vida colectiva y generado nuevas preguntas en torno a este modo particular de habitar. Por ello, cualitativamente no hay un interés por probar una hipótesis, sino se trata de dar cuenta de algunas dimensiones que dan forma a un proceso que pone fin a un modo de habitar y de un sujeto definido física y mentalmente por la condición citadina en medio del Desierto de Atacama, en la medida que las relaciones sociales y productivas dejan de ser local-local o centradas sobre sí mismas, modificando la interlocución e interacción que alimenta los lazos sociales.

En estos términos, los distintos registros realizados en los últimos años, avanzan hacia consideraciones asociadas a las transformaciones urbanas y metropolitanas, preocupaciones que, como sostiene De Mattos (2007), se ubican como preocupaciones centrales de los investigadores en América Latina, y que están asociadas a procesos como la globalización, la informacionalización y reestructuración productiva; ejes que permiten plantearse temas como los de las culturas urbanas, los imaginarios, la hibridación y procesos migratorios (De Mattos, 2007). En el marco de estas directrices, en este estudio de caso se releva la cuestión laboral en relación al habitar, y cómo el enclave productivo se transforma en un lugar que es parte de una red de posiciones que son espaciales y económicas, lo que genera un conjunto de dislocaciones en una ciudad que fue contenedora de la experiencia.

Desde esta perspectiva, asumimos que en la historia del salitre, claramente puede distinguirse un antes y un después desde el punto de vista productivo y de las condiciones de ocupación territorial del Desierto de Atacama, debido fundamentalmente a la implementación de cambios tecnológicos y a la construcción de tres ciudades que modifican drásticamente lo que hoy llamaríamos la "calidad de vida" de la población relacionada con la explotación del nitrato desde el siglo XIX. María Elena (1925-1926), Pedro de Valdivia (1931) y Chacabuco (1924), hoy partes de la II Región, se forman como Company Towns, dentro de las cuales, las dos primeras lideran el protagonismo productivo frente a la decadencia productiva de la antigua provincia de Tarapacá (I Región) a partir de la segunda década del siglo pasado, marcando un quiebre con la imagen de pobreza, injusticia y desolación que se ha quedado en la retina del imaginario social de Chile frente a la explotación del caliche.

Con estas ciudades, se impone la introducción y aplicación de estándares industriales específicos, "para formas de asentamiento en las que subyacen modelos urbanos aplicados a criterios productivos en condiciones locales... pensados y planificados con un alto grado de urbanidad" (Garcés 2007, p. 29); son planeadas antes de ser habitadas. Así, las "ciudades del salitre" —como las llama Eugenio Garcés (1999) — con su sugerente y nueva infraestructura hacen que la 
población proactiva a esta posibilidad se sienta atraída y se estabilice bajo una funcionalidad que opera como totalidad y con importante autonomía, y en esa misma medida, se inaugure la posibilidad de desarrollar un proyecto vital y laboral que parecía no tener fin. Se trata de ciudades inventadas y concebidas en pleno desierto que ofrecieron trabajo, alimentación y vivienda de estándares superiores para la época, a las cuales llegaron a vivir y convivir por décadas hombres, mujeres y familias de distintas tradiciones culturales; con zonificaciones, segregación espacial, y marcas de exclusividad que generan formas de vida homogéneas (por trabajo, status, ascendencia étnica u origen histórico particular) que forjan el "otro" urbano y que hablan de una organización del mundo con categorías densificadas como "barrio americano" o de los chalet, "corrida de los bolivianos", o la de los "buques".

El aislamiento en la infinitud del paisaje desértico, de la mano de los sistemas de regulación altamente formalizados para entrar, salir y permanecer en las ciudades, es lo que con el paso de los años va decantando en una identidad particular y forjando una identificación con las dinámicas interiores, prescindiendo material y emocionalmente del exterior u observándolo muy lejano respecto de su oferta para considerarlo atractivo. Esto refuerza la idea o necesidad proyectiva en relación a la ciudad, en la medida que -siguiendo a Sennett (2001, p. 148)- hay una arbitrariedad en elegir quién es apropiado para vivir en tal o cual lugar, lo que da forma a un sistema de relaciones sociales que durante décadas serán de tipo local-local, con desplazamientos domésticos asociados al comprar, recreativos vinculados a actividades sociales y laborales de acuerdo a roles y turnos, pudiéndose establecer sus horarios y rutinas.

Recogiendo esta formalización de las rutinas, y a partir de una mirada antropológica, sabemos que toda identidad apunta simultáneamente a cuestiones íntimas en las que se juega la individualización como al horizonte de las configuraciones colectivas. Que la identidad corresponde al significante de la diferencia específica, lo que subyace y singulariza, es decir, lo particular de cada uno o del colectivo. Su posibilidad es tal en cuanto existan elementos contrastivos o alter egos que operen como espejos, de modo que pueda tomarse conciencia de quién se es, el lugar ocupado en la estructura social, y responderse desde dónde vengo como dimensión filial. Así, las diferencias internas se ordenan en ME en función de género, edad, ascendencia étnica, calificación laboral y profesional, por secciones de trabajo, barrio, reconocimiento público, y las externas por oficinas salitreras (Coya, Vergara, Pedro de Valdivia u otras) y un genérico no pampino. Sin embargo, por sobre las diferencias, lo que sostuvo la vida al interior de las ciudades del salitre fue la multiplicidad de puntos de contacto y la importante cantidad de actividades y afiliaciones que se expresan en varios tipos y clases de vida en grupo.

Desde esta perspectiva, la pretensión etnográfica en una ciudad que opera como contenedor de la experiencia, y que sustenta esta investigación, se ubica en el orden de una aproximación a la biografía individual y a los elementos que demarcan de manera activa o residual la memoria colectiva asociada a un posicionamiento específico en el espacio, sobre el supuesto de la existencia de una distribución social y desigual del conocimiento propio de toda comunidad. En este sentido, es el territorio compartido lo que impone la interdependencia como praxis, y es ello lo que obliga a la mediación para que puedan desempeñarse los papeles específicos de cada uno; será "la circulación" [de los actores] el vínculo que pone en comunicación al espacio y su materialidad” (Ortiz, 2000, p. 38), estructurando la vida urbana. 
Dentro de estos marcos, hemos observado que no puede entenderse esta identidad e identificación citadina alcanzada en las ciudades del salitre, si no es bajo la idea de un cierto fluir específico del tiempo y de una organización del mismo que estructura y estabiliza la cultura urbana. Y ello está mediado precisamente por la combinación funcional y armónica que logra la concepción de la company town entre el habitar y el trabajar, entre la ritualización de la vida cotidiana y los servicios para hacer la vida, entre los equilibrios del tiempo industrial y el familiar o social, lo que conduce a importantes puntos de encuentro y reconocimiento entre sus habitantes. Esto, ratifica lo que puede encontrase en toda la literatura antropológica, en cuanto espacio y tiempo no son entidades abstractas sino categorías sociales.

Esta legibilidad de lo organizativo temporal promovido desde la empresa y de la distribución funcional del espacio, es lo que proporciona la base y materia prima para que se asienten los símbolos y recuerdos colectivos para la comunicación del grupo (Lynch, 2008), aun cuando no se trata sólo de tiempo cronológico sino de tiempo existencial y anímico. Así es que, en relación a esta apreciación organizativa que en el registro se presenta como saturado de actividades y eventos, que son también la entrega de cierta "seguridad emotiva" como parte de un contrato social, que pueden -con vicisitudes en perspectiva- marcarse los hitos que fijan el paso de los años en el asentamiento, la intensidad de algunos procesos, lo desaparecido, lo relevado, lo querido, lo extrańado; lo que hará emerger silencios y hiatos, espacios crepusculares, móviles y escindidos en relación a la propia vida y la experiencia del modo de vida urbano. Todo pasado siempre se practica en el presente, y toda imagen contingente de la ciudad será en relación a la mejor idea que de ella se tenga, mediada por una cierta distancia y por ese tiempo anímico y existencial.

A partir del registro etnográfico y la aplicación de algunos instrumentos estandarizados ${ }^{1}$, la identidad de los habitantes de María Elena se encuentra anudada en términos macro al desarrollo de la explotación del nitrato y a la industria del salitre como forma de penetración y apropiación del desierto; y micro, al diseño de una ciudad imaginada, como una página en blanco que comienza a ser bosquejada prescindiendo de las condiciones biofísicas, y que ante todo ofrece seguridad. En María Elena hay una prolija planificación, lo que constituye la plasmación inevitable de una imagen urbana sobre el territorio, a la que concurren muchas identidades a darle su forma. Ello es lo que permite observar la identidad como un autoconcepto totalizador, un sentido de continuidad de las experiencias a lo largo del tiempo y la coherencia de sí mismo aunque los contextos cambien.

Entonces, se fijan criterios de un urbanismo operativo y funcional, de alto impacto social, económico y territorial en el marco del desarrollo del capitalismo industrial. Se combinan instalaciones para la industria, habitaciones y un conjunto de servicios propios para garantizar la reproducción biológica y social de la comunidad en la vida cotidiana, y a partir de esta estable complementariedad y funcionalidad, todo cambio en la industria afectará decididamente la

\footnotetext{
1 Encuestas a jefes de familia y estudiantes, como parte de un estudio descriptivo no experimental y prospectivo. Buscó establecer, en lo posible, la mayor cantidad de factores asociados al sistema educativo, al contexto socioeconómico y variables sociales y culturales en la ciudad. La muestra está constituida por 268 familias y 68 estudiantes de $4^{\circ}$ medio.
} 
relación simbiótica entre los habitantes y la ciudad. Asimismo, se debe resaltar la importancia que poseen estas ciudades como contribución al desarrollo de la vivienda obrera en nuestro país y a la experimentación con nuevos materiales adaptados a las condiciones locales.

En relación a lo señalado, más allá del paisaje, y de lo propiamente infraestructural y arquitectónico que se representa en el espacio (véase Garcés, 1999; 2007), de modo etnográfico e histórico, o si se quiere como argumento antropológico, lo importante de ser observado, valorizado y respondido es: ¿qué es lo que se construye de manera paralela a la ciudad planificada? ¿Qué es necesario para que ésta sea operativa y funcional desde las personas que la van a habitar? La respuesta es categórica. Se construye una institucionalidad ad hoc a esta concepción urbana y un universo conversacional relativamente autónomo, con muchas claves, y regulaciones que marcan las posibilidades de permanencia y de constitución de un proyecto vital, y de alguna manera autosuficiente, cuyas referencias más substanciosas se constituyen en el cotidiano, en el día a día, en las rutinas y rituales obligados que demanda la vida en una condición de cierto aislamiento y con importante infraestructura, pero autárquico para que los habitantes atraídos desde lugares disímiles puedan ser retenidos. En este sentido, sabemos, las instituciones - con el correr del tiempo- "crean comportamientos y culturas", por lo que hay "usuarios" y "defensores" de las mismas (Lucena, 2006, p. 210), cuestión que -finalmente- da sostén al logos de una comunidad y una inteligibilidad a su orden estético. Por ello, desde la perspectiva de la memoria colectiva y la memoria histórica, ME se transformó en la "buena moza" de la pampa: una ciudad sobria, elegante, cuidada, completa, conocida y querida por quienes vivieron o han vivido por décadas en ella.

En esta perspectiva, todo el registro etnográfico y la documentación indican que lo que se requería en términos de servicios urbanos estaba disponible dentro de los márgenes de la ciudad (hospital, escuela, biblioteca, carabineros, almacenes, teatro, salones), inclusive aquello que excedía a la satisfacción de las necesidades básicas ${ }^{2}$. La conexión e intercambio con las otras oficinas del entorno que constituían el alter ego de María Elena, estaba dada por relaciones empresariales, deportivas y familiares, reconociéndoles a éstas y sus habitantes méritos de distinta índole, pero también rivalizando con ellas ${ }^{3}$. Claramente, en ME desde o hacia la plaza hablamos de puntos de contacto iguales para sus habitantes, donde cualquier ruta que se tome por parte de un usuario de la ciudad no implica por su geometría más de 1.000 metros de camino, por lo que tiempo, rutinas y lugares dan forma a una intrincada topofilia y proxemia que da forma a una narración colectiva de la experiencia y sus vicisitudes, lo que revela desde la perspectiva del presente cuánto se ha perdido o ha desaparecido para siempre.

\footnotetext{
2 Más de 20 disciplinas deportivas se practicaron. Hubo teatro, cine, Instituto Chileno Norteamericano de Cultura, filarmónica, radioteatros, visitas de delegaciones deportivas y culturales extranjeras, festivales y fiestas de la primavera.

3 Esto puede rastrearse en comparaciones aún vigentes en el disperso imaginario pampino, de amplio espectro, y que van en un comienzo desde los accidentes laborales, las horas perdidas en las faenas, la productividad, el complejo urbano, para más tarde pasar a juicios de valor sobre los hábitos y conductas de sus habitantes, y con más intensidad sobre las hazańas y glorias deportivas.
} 
De modo particular, será la calle con su conjunto de actividades, no la habitación, lo que domina la ciudad del recuerdo porque la vivienda cumplió exclusivamente una función residencial. La vida se hizo puertas afuera, lo que ocultó o no constituyó en problema las dimensiones de la vivienda, aun cuando estas eran de nivel superior a las conocidas o a las que podían acceder en la época los sectores obreros.

Figura 1

MAPA DE UBICACIÓN DE MARÍA ELENA

Oficinas Salitreras de Antofagasta

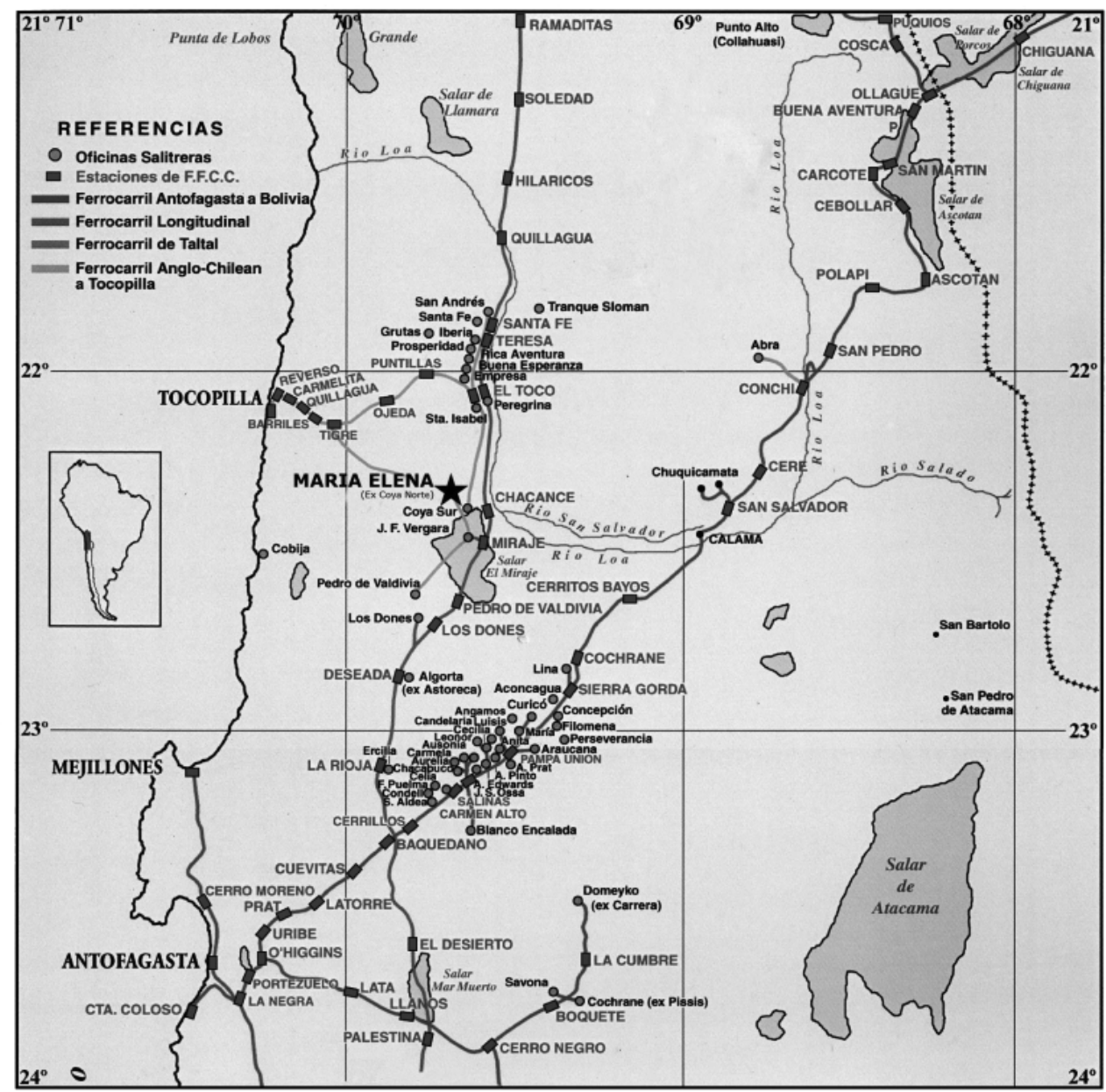

Fuente: Adaptado de álbum desierto

Analíticamente, la identidad de los habitantes en relación a la ciudad se encuentra asociada a dos cuestiones que tempranamente toman distancia de la historia del salitre de fines del siglo XIX y comienzos del XX, ya que se trata de asentamientos urbanos de una nueva generación, porque los antiguos campamentos salitreros estuvieron siempre "destinados a desaparecer" (véase González Miranda 2006, p. 193). Por una parte, tras la puesta en marcha de la ciudad 
encontramos el despliegue de un esfuerzo pedagógico civilizatorio empresarial que posee rasgos protestantes -por su fuerte énfasis en el valor del trabajo-, con el objetivo de asimilar y disciplinar a los hombres y mujeres que llegan con diversas historias y experiencias de vida a integrarse a la construcción de un espacio social y cultural urbano e industrial, que son los elementos constitutivos fundamentales al momento de proporcionar a este espacio su propio y distintivo contenido simbólico. Por otra, esta construcción simbólica se afianza y liga -para ser efectiva- a un espacio inicial de contención y de regulación del movimiento físico de la población, es decir, se establece una frontera mental y material, como línea divisoria, o categoría divisoria, y expresión de un circuito de comunicación volcado sobre sí mismo y separado con el exterior, porque — en este caso - la frontera es concebida como una forma de protección y un signo de exclusividad, frente a chimeneas que se apagaban, una pampa que se despoblaba y asentamientos industriales que se cerraban en toda su extensión. Esta condición se encuentra disociada de la historia misma del salitre, para que ésta pueda someterse a los nuevos imperativos empresariales en el marco de la llamada "cultura Guggenheim".

Introducimos la idea de cultura Guggenheim para referirnos a la implementación de una nueva y moderna forma productiva (aplicaciones tecnológicas para trabajar con mineral de más baja ley), menos trabajo físico y correlatos sociales que implican sistemas de protección social, que se hacen acompañar por el Código del Trabajo y por los beneficios asociados al goce y usufructo de las diversas instalaciones urbanas.

El lucro como objetivo empresarial, se consuma en la medida que la ciudad pudo - como estaba previsto - ser autosuficiente y eficiente en sus relaciones locales y exteriores, es decir, que el proyecto infraestructural y su planificación, de la mano de los objetivos productivos pudieron mantenerse por décadas atractivos y vigorosos para contener dentro de sus márgenes a los trabajadores y las familias (Rodríguez, 2004), lo que implica también una política de relaciones industriales modernas como producto histórico de la acción de los actores. Esto presupone una cuestión central: una política de pleno empleo para la población económicamente activa y subsidiaria para quienes son dependientes, lo que justifica la existencia misma del complejo urbano (Rodríguez, 2004; Rodríguez y Miranda, 2008).

Así como hay una concepción urbana de totalidad, también la hay respecto de la sociedad. Existe una pretensión homogeneizadora de amplio espectro, con fuerte énfasis en marcar diferencias entre el adentro urbano y el afuera, lo que corresponde a la ambición fundacional de un orden laboral que otorga pertenencia y reconocimiento social, económico, político, doméstico, familiar, recreativo, social y cultural, coherentemente estructurado como un todo y asociado a un conjunto de valores éticos primordiales como el sentido del deber (familiar y laboral), la responsabilidad con sí mismo y los demás, y con el cuidado de los recursos, la maquinaria y las herramientas, la vivienda y la infraestructura de la ciudad. De este modo, observamos que la empresa está en todo, lo penetra y recorre todo; porque la homogeneización en los enclaves mineros siempre es una cuestión vital para la generación de una "cohesión social" y fortalecer una identidad, ya que las interacciones y asociatividad se dan de manera siempre dual, tanto dentro y fuera del trabajo (Zapata, 2002), lo que resulta muy coherente con la pretensión de ser una ciudad sui generis (inventada según principios utópicos), privada y con la propia definición de pampino y elenino dada por los más antiguos habitantes, y que 
otorgan el status de tal a un hombre, mujer o familia en el haber nacido en la pampa o tener una larga permanencia en ella ${ }^{4}$.

De manera clara, para dotar de efectividad el proyecto productivo-urbano, éste se construye con la idea del "bienestar social integrado", concepto no conocido ni implementado en el país (González Pizarro, 1997; 2003). Se establecen fórmulas y ejes que comienzan a configurar un nuevo mundo en torno al salitre, con claves muy distintas a lo conocido y aquello en lo que ha puesto el énfasis la agenda histórica del siglo XIX y comienzos del XX, o aquello en lo que han insistido formatos musicales y literarios. Ahora, se trata de un mundo moderno en su expresión más radical: urbano, social, tecnológico y laboral. Es decir, hablamos de sistemas de protección en salud, vivienda, alimentación, educación y previsión; nuevos procesos productivos y aplicaciones; y, regulaciones laborales inscritas dentro de las políticas de Estado 5 .

Entonces, el proyecto de ciudad es de largo plazo y está asociado a un proyecto de vida. La explotación del nitrato se pone en marcha y se vuelve sustentable a partir de la internalización progresiva del conjunto de principios ético-normativos respecto al comportamiento local, lo que va dando forma al modo de ser urbano y a la seguridad existencial en torno a la ciudad. A través del acatamiento de estas regulaciones internas (reglamentos) y la legislación laboral es posible contar con trabajo y usufructuar y gozar de las instalaciones y servicios ofrecidos por la Compañía en el marco de la constitución de la ciudad, lo que resulta muy coherente dentro de los marcos de una sociedad industrial donde lo laboral es la base de la integración, de la supervivencia y de la individuación.

En términos diacrónicos estos ejes estabilizan a los trabajadores y sus familias a partir del otorgamiento de un conjunto de beneficios -como la vivienda, alimentación subsidiada, el vestuario de fácil acceso y mecanismos de ascenso laboral- desconocidos en general en el país y por los propios obreros del salitre, lo que favorece el asentamiento de bases estructurantes de la vida colectiva, ayudando a armonizar, contener y conducir durante décadas las expectativas de los habitantes y dar sustentabilidad a la ciudad, lo que se expresa en códigos escritos (distintos reglamentos) y principios de uso social tanto en las interacciones generales como intrafamiliares.

La claridad y fuerza de este ejercicio y aprendizaje pedagógico de construcción de un tipo de ciudadano que se encuentre, en lo posible, desafectado de lo que acontece en el exterior (movimiento social) y que reconozca los ingentes esfuerzos que hace la Compañía para que goce junto a su familia de altos estándares de bienestar, es lo que decanta en su estrecha ligazón con el paisaje, con sus compañeros de trabajo y vecinos, con las horas del día, con los eventos colectivos, con el descanso, la recreación y fundamentalmente la apropiación, identificación y compromiso con la ciudad. En síntesis: por una parte, hace visible a María Elena, le da reconocimiento, coherencia y homogeneidad, y la convierte simultáneamente en polo de atracción

\footnotetext{
4 Encontramos esta misma apreciación en las referencias hacia la vida de Sewell, Chuquicamata, Pedro de Valdivia, El Salvador, Potrerillos.

5 Tenemos una condición similar a lo experimentado en otras áreas de la minería como es el caso de Chuquicamata y en Sewell.
} 
y de retención para quienes deseen realizar un proyecto de vida; por otra, la hace querible, en la medida que se le recorre, usa y reconoce en cada uno de sus rincones sin temores (véase Rodríguez, 2004). Así, se constituye una comunidad de destino que da forma al "nosotros", la ciudad se vuelve sustentable, en la medida que hay una imagen integrada entre el trabajo y la ciudad, y las ocupaciones y preocupaciones son compartidas en relación al presente y al futuro. Se sabe de límites mentales y físicos, cuántos somos, quiénes somos, cómo somos y de qué nos preocupamos.

La proyección de la vida en términos locales forja una "comunidad de destino", que, por sobre todo, es una construcción política, pero también una abstracción simbólica, que como comunidad imaginada (véase Anderson, 2002) tiene componentes simbólicos que permiten forjar la idea de un "nosotros" en el espacio local y diferenciarse de "otros" desde un lenguaje, cultura y sistemas simbólicos, con componentes metonímicos y metafóricos que permiten articular las individualidades y dar soporte a la comunidad urbana.

De este modo, se afianza un estilo de vida citadino fundado sobre dos dimensiones. Por una parte, sobre condiciones materiales que aseguran la supervivencia, definidas por el trabajo, el salario y su estabilidad; por otra, sobre consideraciones simbólicas, asociadas al prestigio de sus habitantes. Ambas dimensiones se articulan en relaciones particulares y amplias como trabajo y consumo, trabajo y prestigio, trabajo y vivienda; $y$, dan paso a un juego de interacciones recíprocas donde el estilo de vida se expresa como materia prima de la economía simbólica, como elección de consumo y como política de identidad en una apropiación diaria del espacio en el que se reconoce su utilización y las relaciones con él, se le integra como vivencia, se le marca y se le puede transformar, porque se vive en él y para él.

\section{De la protección a la privatización}

De la mano de un cambio de administración de la propiedad de la Compañía, en las postrimerías del siglo XX, la original pretensión "civilizatoria” u "homogeneizadora” llega a su fin con la privatización en $1988^{6}$. Con una nueva política empresarial en torno al trabajo y al complejo urbano, la ciudad se abre al exterior de manera nunca vista, lo que constituye un rasgo inédito dentro de los marcos de una urbe estable que era sentida como propia y dominada física, psicológica y económicamente por toda la población, aunque nada les pertenecía. En términos efectivos, sus habitantes señalan que "podían vivir sin dinero", ya que la pulpería les surtía de todo, lo que era descontado posteriormente en el pago; asimismo, desaparece lo que ofrecía la vida pública, por lo que se produce una nueva fijación espacial: sin eventos públicos que convoquen a los nińos, jóvenes, viejos, mujeres, hombres, trabajadores y trabajadoras, la habitación se vuelve más relevante. Esto anuncia, como elemento nuevo, una meditada reflexión y crítica sobre la vivienda.

\footnotetext{
6 Las distintas administraciones corresponden a la Compañía Salitrera Anglo Lautaro — de capitales norteamericanos_- la que se convierte en sociedad mixta con el Estado de Chile — a través de CORFO_ en mayo de 1968 (62,5\% frente a 37,5\%), para luego en 1970 la CORFO alcanzar el control de Compañía con el 51\%, y en el mismo año lograr el 70\%. En 1971, el Estado de Chile logra el 100\% de control, para luego ser privatizada en 1988.
} 
La ciudad nunca necesitó crecer tan significativamente en metros cuadrados habitacionales, porque la vida se hacía en los exteriores. Sin embargo, cuando desaparece la planificación estratégica sobre la vida social, y se reconfigura el patrón integrativo desde el exterior al interior, se hace evidente la incomodad y la insuficiencia del espacio cuando el consumo cultural se da en la vivienda, la que ahora es observada en sus reales dimensiones, estigmatizándola como "pequeña”, “estrecha”, “con poca privacidad”, "insuficiente”, "deteriorada”, "vieja”.

Con la privatización se cierra Pedro de Valdivia, su par, que constituía su alter ego. Con ello se producen importantes reajustes laborales, infraestructurales y existenciales, tanto en la plantilla de trabajadores (flexibilidad numérica y funcional de la misma), en las prestaciones sociales históricas (pulpería y productos básicos) y en los servicios subsidiados (agua, luz eléctrica, arriendo, asignaciones de viviendas), y una no menor reestructuración del estilo de vida (deporte y recreación) y del uso y canalización del tiempo de ocio, de las formas de reproducción social y biológica, y de la representación de sí mismos en la medida que la ciudad se debe abrir demográficamente a un amplio espectro de nuevos trabajadores "nómades" provenientes del exterior de la pampa y que llegan en forma de subcontratación, con distintas calificaciones, asociados a otras experiencias laborales, historias, identidades y valores, renovando las formas de relación y las orientaciones sobre las que descansaba la sociabilidad y el uso de los espacios. Se redefine el conjunto de los espacios comunitarios y usos de los inmuebles, algunos entran en desuso, se congela la política de otorgamiento de viviendas a familias, se contiene la inversión social, y de manera cada vez más acelerada, aparece la figura del riesgo, la inseguridad y la desconfianza, en cuanto los nuevos actores alertan y dan cuenta de la prescindencia de los habitantes y trabajadores históricos, como un rasgo nuevo para los trabajadores y sus familias ${ }^{7}$.

De este modo, el "extraño", el contratista o trabajador "terciarizado" que irrumpe y participa de este espacio, se constituye desde el discurso local en una idea simplificada de la amenaza que se deja caer sobre la ciudad, en la medida que con él llega la idea del fin de los empleos estables y sindicalizados, y el crecimiento de empleos de carácter flexible no asociados a la urbe. Esto produce un importante simbolismo generativo, un ordenamiento de la diferencia en categorías sencillas y generales, basadas en estereotipos sociales y prejuicios sobre la "extranjería", lo que permite hablar de otras cosas y preocupaciones como restricciones o pérdidas de servicios garantizados y movilidad social hacia abajo en algunos casos, o plantearse cuánto me pertenece después de décadas en la ciudad; su figura representa una variedad de cambios locales que resultan preocupantes e incontrolados, en la medida que esta economía de servicios contribuye a producir las circunstancias causantes de los temores y del deterioro social. La simplificación de la amenaza permite reordenar el mundo y procurar una sensación resistente -en algunos casos- de que "todo está bajo control", aunque el mundo local ya no pueda dominarse porque se producen procesos de confinamiento, y la experiencia inédita de comenzar a vivir presionados en una periferia, porque ahora lo importante son los trabajadores (“colaboradores") y no las familias.

Así, entre otras cosas, el índice de masculinidad llega a 1.32, lo que revela la presencia de menos familias y el ingreso de hombres solteros de la misma empresa SQM o subcontratados, no residentes permanentes. 
En lo sustantivo, la apertura de esta coherencia urbana que se presentaba sin fisuras, indica que la homogeneidad social y cultural ya no es necesaria ni un requisito para la sustentabilidad de un proyecto económico productivo anclado a redes globales. El modelo primigenio de la uniformidad discursiva como conciencia de un "nosotros" y como vaciado histórico de experticia laboral, y su acatamiento en el día a día, no es fundamento básico para la productividad eficiente de una compañía como lo fue en el pasado (y no podía ser de otra manera), ni condición necesaria para la existencia de una ciudad. Hoy, contrariamente, lo estratégico del proyecto productivo y su sustentabilidad es la diversidad en un amplio rango cultural y de calificación educacional y laboral de quienes se vinculan con la empresa y la ciudad a través de servicios de subcontratación.

Lo señalado, queda demostrado en cómo se configura la actual pirámide de población.

Figura 2

PIRÁMIDE DE EDADES DE MARÍA ELENA

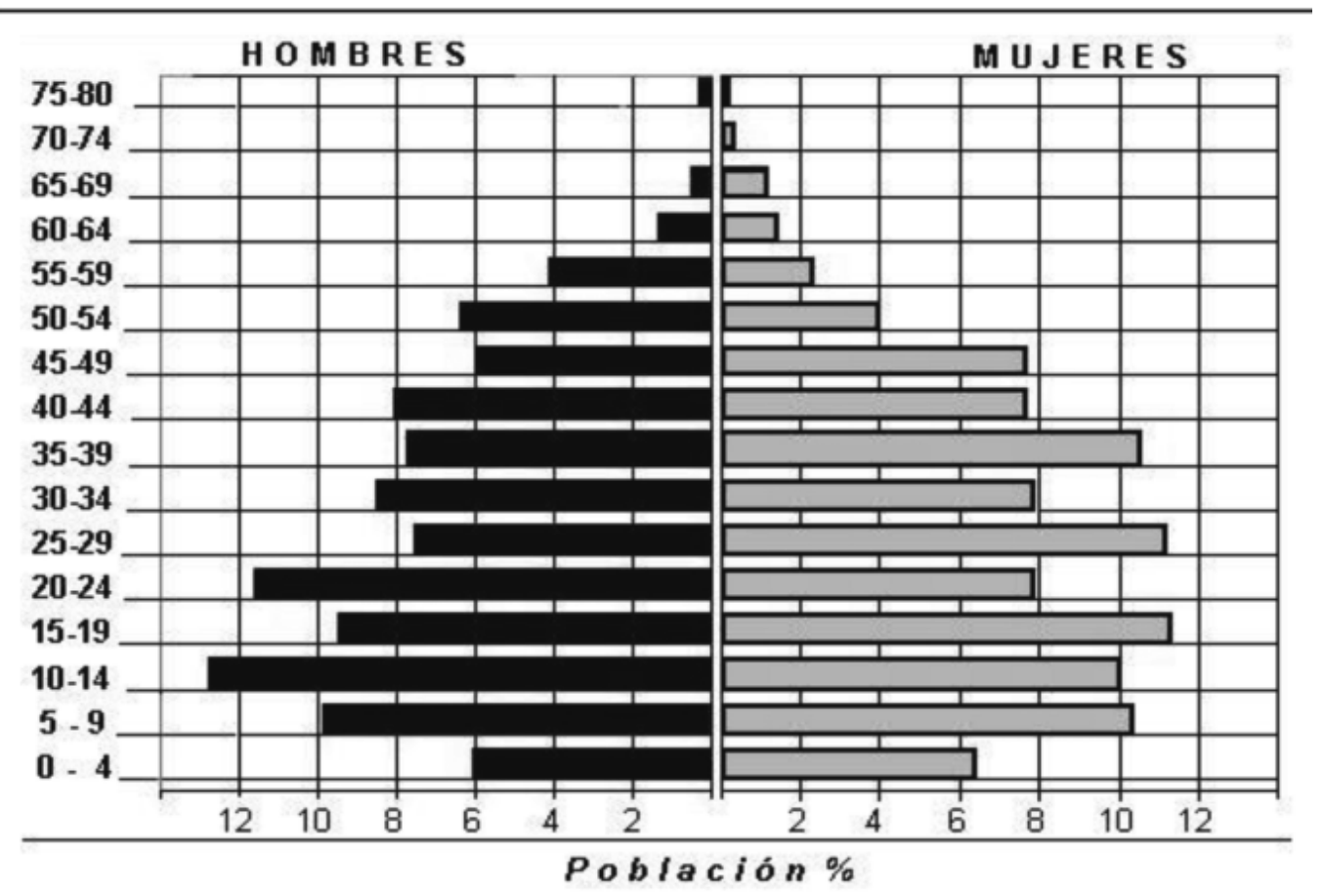

Fuente: Tomado de Mandujano 2007

En este gráfico, se pueden apreciar tres cuestiones relevantes a las que ha apuntado el trabajo del sociólogo Fernando Mandujano:

- El bajo porcentaje de mayores de 60 años, debido a que la permanencia en la ciudad sólo se da mientras las personas se encuentran en su etapa productiva. La jubilación es seguida por la emigración.

- Un sobredimensionamiento de la población económicamente productiva ( 15 a 60 años) y de los que se encuentran en edad fértil, donde el $64 \%$ de la población se encuentra 
entre los 15 y 49 años, mientras que el Censo de Población de 2002 indica que a nivel nacional la cifra se ubica en $53,9 \%$

- Que existe un fuerte estrechamiento de la base, lo que es propio de las pirámides de población en declinación (Mandujano, 2007).

\section{Trabajar, comer y dormir}

Los trabajadores externos se encuentran disociados de la ciudad, del habitar —al modo heideggeriano- - en cuanto el uso de las construcciones sólo los domicilian (2007, p. 28), manifestándose en una alteración de la circulación cotidiana, la velocidad de la vida y una ruptura con el continuum espacial, ya que sólo se trata de trabajar, dormir y comer.

Son éstos, a partir de una nueva racionalización del espacio, quienes contribuyen a acentuar la discontinuidad de la visión colectiva al usar viviendas antes consagradas al goce familiar y reforzar un sentimiento de desplazamiento y debilitamiento de la autoestima de los actores locales en cuanto ya no se es ni puede ser dominador del lugar. Así, la mitología de la identidad sustentada en el apego a la ciudad, se ve alterada en sus relatos, y aparecen lecturas sobre los peligros que llegan con estos nuevos trabajadores (aunque el índice de criminalidad sea nulo), las angustias, las soluciones y las ideas. Su presencia trae consigo un empobrecimiento simbólico de las claves tradicionales de la cultura urbana local y de la propia gramática de la autenticidad, y la adopción inevitable de otros elementos significantes foráneos que llegan a través de la masificación del TV cable o traídos por los innumerables trabajadores de las empresas contratistas ${ }^{8}$. Se suma a lo anterior, la percepción del evidente deterioro material de la ciudad y sus inmuebles más emblemáticos (teatro, sedes sindicales, escuela), la "suciedad" y el "abandono", lo que ratifica la importancia que posee la cultura en la estructuración del espacio. Asimismo, con fuerza emerge una reorientación existencial y valórica -entre sus habitantes-, expresada en una unidimensionalidad de las aspiraciones, aun cuando sabemos éstas son individuales, pues en nada se diferencian de las expectativas de los ciudadanos de las otras urbes, como muestra del débil aprecio por lo que queda de la ciudad y de la fuerza que tienen los mecanismos de expulsión y atracción. En estas combinaciones se enfrentan necesidades socialmente construidas y emergen valores como el de la "propiedad", asociados al tener una vivienda "propia” y una búsqueda de los mecanismos para ello.

Ya no hay una marca pública viva que indique que se está en una ciudad del salitre, sino sólo en una ciudad vieja. Hay una asintonía entre la ciudad de las pupilas, los edificios e infraestructura no utilizada (teatro, escuela, sedes sindicales, mercado), las ruinas y abandono como evidencia de una función perdida, las narraciones en torno al salitre de sus habitantes y una empresa multinacional. Los detalles contados por sus habitantes son anómalos en relación a la geografía de la ciudad, porque los signos, aunque son familiares, son extraños.

Se trata de una diversidad laboral y cultural que irrumpe sobre un mundo urbano que por décadas presentó rituales, armonía, consistencia y coherencia desde el punto de vista de una

$8 \quad$ Entre estos, la preocupación por el delito, como parte de una cultura del miedo que llega a través de la TV. 
cierta carrera social de los trabajadores ligado a un proyecto de vida, apoyándose en el marco de las macrotransformaciones instaladas en el mundo del trabajo: derecho laboral, localización laboral, horario laboral. Se trata de una nueva filosofía del trabajo, de formas plurales de sistemas de turnos, contratación y sub-empleo; especialización que permite como modo estandarizado de razonamiento de la empresa (Linhart, 2007, p. 26), una alta y cada vez más refinada eficiencia en el uso de todas las instalaciones de la ciudad de manera compacta, flexible, funcional, intensa, parcial y prolongada por las distintas diversidades laborales históricas y no históricas.

Cuando en este proceso post privatización se redestinan muchas de las viviendas familiares para el uso de personas solas o cuadrillas de trabajadores externos, y se acaba la vida exterior ligada a la programación de actividades familiares y las diferenciadas por género y edad, se produce la salida y desafiliación de importantes grupos familiares de ME y la discontinuidad del proyecto vital, pues no hay a "dónde ir" y a "qué salir". Hoy el trabajo y los objetivos productivos tienen autonomía en relación al habitar la ciudad.

\section{Población y sustentabilidad de un proyecto vital}

Lo señalado hasta aquí tiene un fuerte impacto en términos demográficos como se puede apreciar en el cuadro siguiente. Este nos indica el comportamiento histórico como las proyecciones futuras de la población a partir de lo que ha significado el fin del pleno empleo y la implementación de sistemas de turnos y la subcontratación, en la medida que hoy no existe relación entre trabajar en o para la compańía y habitar la ciudad de manera permanente. Todo trabajador está siempre en condiciones de partir, porque es prescindible.

\section{Figura 3}

\section{EVOLUCIÓN HISTÓRICA Y PROYECCIÓN DE LA POBLACIÓN EN MARÍA ELENA}

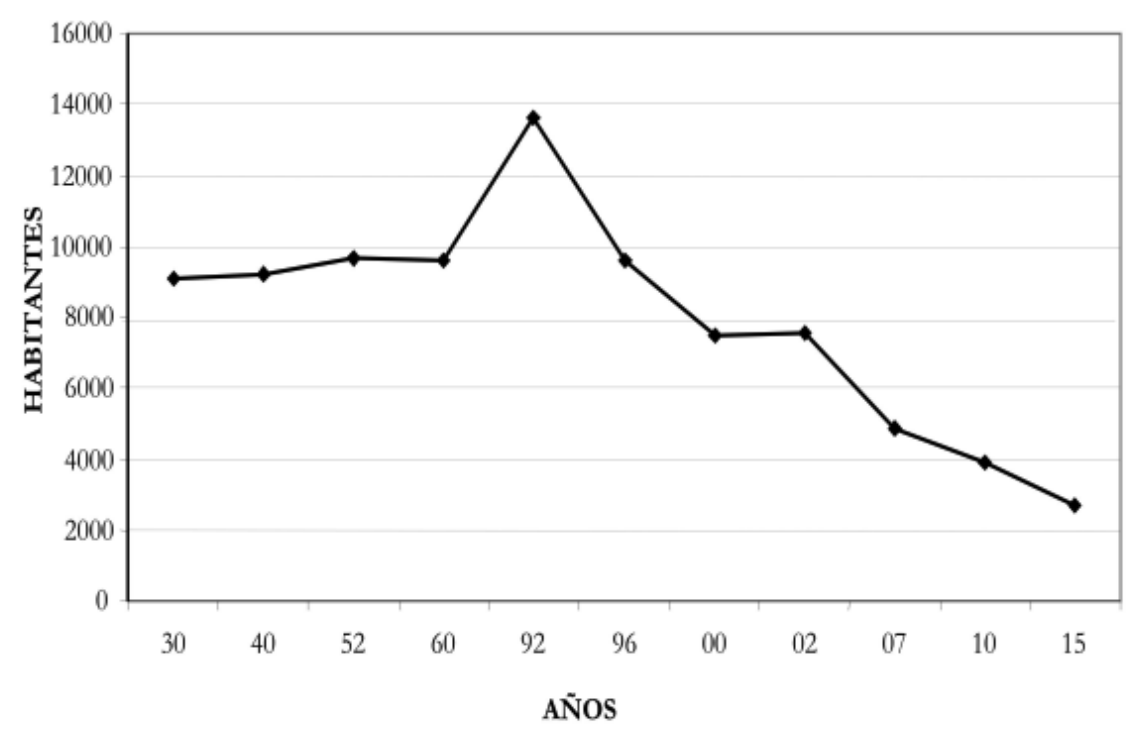


A partir de las cifras indicadas en el cuadro 2, debemos reconocer una fractura respecto de la compleja necesidad fundacional de la ciudad asociada al pleno empleo. La población transita de la seguridad a la inseguridad, y con impactos múltiples que se hacen sentir en el espacio urbano, y que va desde lo doméstico familiar al pequeño comercio que se vuelve insustentable frente al despoblamiento y frente a la alimentación a escala otorgada a los trabajadores de los distintos turnos, consolidándose una progresiva individuación a través del trabajo configurada en una secularización de dicha esfera de otras dimensiones objetivas y subjetivas a las que estaba integrada y que inspiraron la concepción de ciudad. En este nuevo esquema no hay lugar para un proyecto vital, familiar, la formación de redes, la asociatividad, la cooperación, la construcción de ciudadanía, la formación de un sujeto colectivo y la imagen del futuro con un anclaje local. Se instala todo lo contrario a lo que podemos encontrar en las innumerables referencias orales y documentales ligadas al propio devenir de ME y la historia del salitre, lo que subvierte la imagen de una cultura e identidad fundada en base al diseño de una company town, a la explotación de un recurso específico y en un modo particular de trabajo, y de relaciones laborales fincadas en relación a la ciudad en el marco de un paisaje que define la existencia y la identidad.

Con el paso desde el pleno empleo a formas flexibles de empleabilidad no hay lugar para la pervivencia de la ciudad histórica que se encuentra en el imaginario, se introduce una nueva ética del trabajo, se modifican substancialmente las formas de interacción social y de ocupación del espacio y la infraestructura, pudiendo resaltarse las siguientes cuestiones básicas como fenómenos en curso, las que hablan de la desafiliación y atomización de sus habitantes en relación al uso de la ciudad.

- Se instala la fragmentación de la unidad de visión y de las condiciones de apropiación del espacio físico y social. Cada actor legitima sus propios discursos y a través de ellos su relación con la ciudad.

- Se manifiesta -como nunca- un abanico muy heterogéneo de afectos, certezas y juicios sobre la condición de la ciudad, destacando una ausencia de proyecto vital ligado a ella. Por tanto, podemos hablar del surgimiento de mitografías alternativas, que cuestionan la continuidad de un discurso y la continuidad de la experiencia en la lógica narrativa sobre la ciudad y en torno al salitre, lo que habla de cómo imaginan hoy su identidad los distintos actores.

- Los objetivos productivos abren la posibilidad de contratación a individuos que no están asociados históricamente a ME ni a la pampa, por lo que son forasteros sin anclaje a la tradición salitrera ni les interesa. Esto profundiza la idea de que el mito del salitre es algo "histórico", entendiendo con ello que se trata de algo "antiguo".

- La flexibilización laboral permite compensar sin dificultad y rápidamente el proceso de desvalorización y obsolescencia del conocimiento de los trabajadores antes anclados a $\mathrm{ME}$, lo que estimula la recurrente renovación de la población y la circulación de nuevas experticias laborales provenientes de distintos lugares, lo que debilita los compromisos con los compañeros, la ciudad, el espacio y el lugar.

- La fragmentación del trabajo en diversas empresas de subcontratación altera y debilita la posición, el poder y la capacidad de negociación histórica de los trabajadores sobre lo salarial y comunitario, en cuanto a partir de sus objetivos y arraigos se vuelven irreconocibles 
unos con otros. Asimismo, hay una gran diferenciación de estatus entre los trabajadores llamados "empresa" (SQM) y todos los "otros", e inclusive celan y se diferencian muy estratificadamente entre quienes coparticipan de las distintas exigencias directas e indirectas de la Compañía SQM en relación a sus objetivos productivos. Con esta lógica dicotómica, los subcontratados son otros inferiorizados como parte de una sociodiferenciación, por lo que la diversidad de quienes coparticipan en la gestión productiva de SQM genera nuevos equilibrios de poder entre la Compañía, sus propios trabajadores y los trabajadores terciarizados.

- Dentro de los marcos de diferenciación, a los trabajadores de SQM se les llama "colaboradores", y como tales y "privilegiados" deben internalizar clara y comprometidamente los objetivos e intereses de la compañía como también sus valores y su ética, pero, ya no aquellos ligados a la ciudad.

- En la ciudad ya no están todos los que ayudaron a forjar el mundo social y cultural; algunos están definitivamente fuera y otros, aunque puedan alojar ahí por 4, 5, 6, 10 ó más días, mantienen relaciones exclusivamente pragmáticas, utilitarias, e inclusive estas pueden llegar a ser inexistentes con la ciudad. El movimiento social, el desarrollo urbano, la vivienda obrera, la colonización del desierto, no es más que un dato histórico o anecdótico.

- La disminución de la población, entra a poner en cuestión una de las cuestiones más insólitas: la existencia de un municipio en un territorio privado, o si se quiere, una de las formas específicas de presencia del Estado en el territorio.

De este modo, la ciudad originaria con su armonía, sus contrapuntos y el universo conversacional fundado y estable por décadas decae a la luz del desarrollo tecnológico, de nuevas formas de estructuración del mundo del trabajo, de la demanda de calificación de los trabajadores, con lo que su antigua población (la que ha realizado ahí su ciclo vital) en gran medida se ve liberada del celo y de la mirada que permitió su estabilidad durante décadas en el orden de 10.000 personas (véase Rodríguez, 2004). Se reduce el número de familias históricas, y comienza un proceso acelerado de recambio de familias por trabajadores solteros, con actores que deben reconfigurar la propia identidad y los tipos y calidad de las relaciones, sumado a un desajuste institucional de amplio espectro que alcanza lo educacional, familiar, axiológico y sindical, pero que también entra en un proceso acelerado de incertidumbre y riesgo, y de desvalorización del saber de sus trabajadores. Tan solo desde el punto de vista de la matrícula escolar, hay una disminución desde unos 5.500 alumnos en 1990, a unos 1.500 en el año 2006.

En este sentido, el espacio urbano comienza un acelerado proceso de reescritura, en cuanto acentúa el juego entre la materialidad y la vida que le anima. Los elementos “indisolubles" y "solidarios", y también "contradictorios" entre los sistemas de objetos como la infraestructura de la ciudad y los sistemas de acciones, es decir, las relaciones e interacciones sociales, promueven la disolución y recreación de formas y contenidos de las configuraciones territoriales para crear el espacio (véase Santos, 2000). La inscripción de los cuerpos de sus hombres y mujeres en el espacio entra en una nueva lógica espacial, ya que muchos mantienen relaciones atópicas.

Lo señalado puede apreciarse en el siguiente cuadro, el que indica distintas relaciones tempoespaciales con la ciudad, las que demuestran la reescritura del espacio hasta cuestionar el sentido 
de continuidad de la vida, visualizar distintos actores y la dificultad para interactuar entre las microhistorias de cada uno, en la medida que se configuran anillos inconexos y volcados sobre sí mismos, con rutinas desconocidas e impermeables por otras.

\section{Figura 4}

\section{MOVIMIENTO DE LA POBLACIÓN}

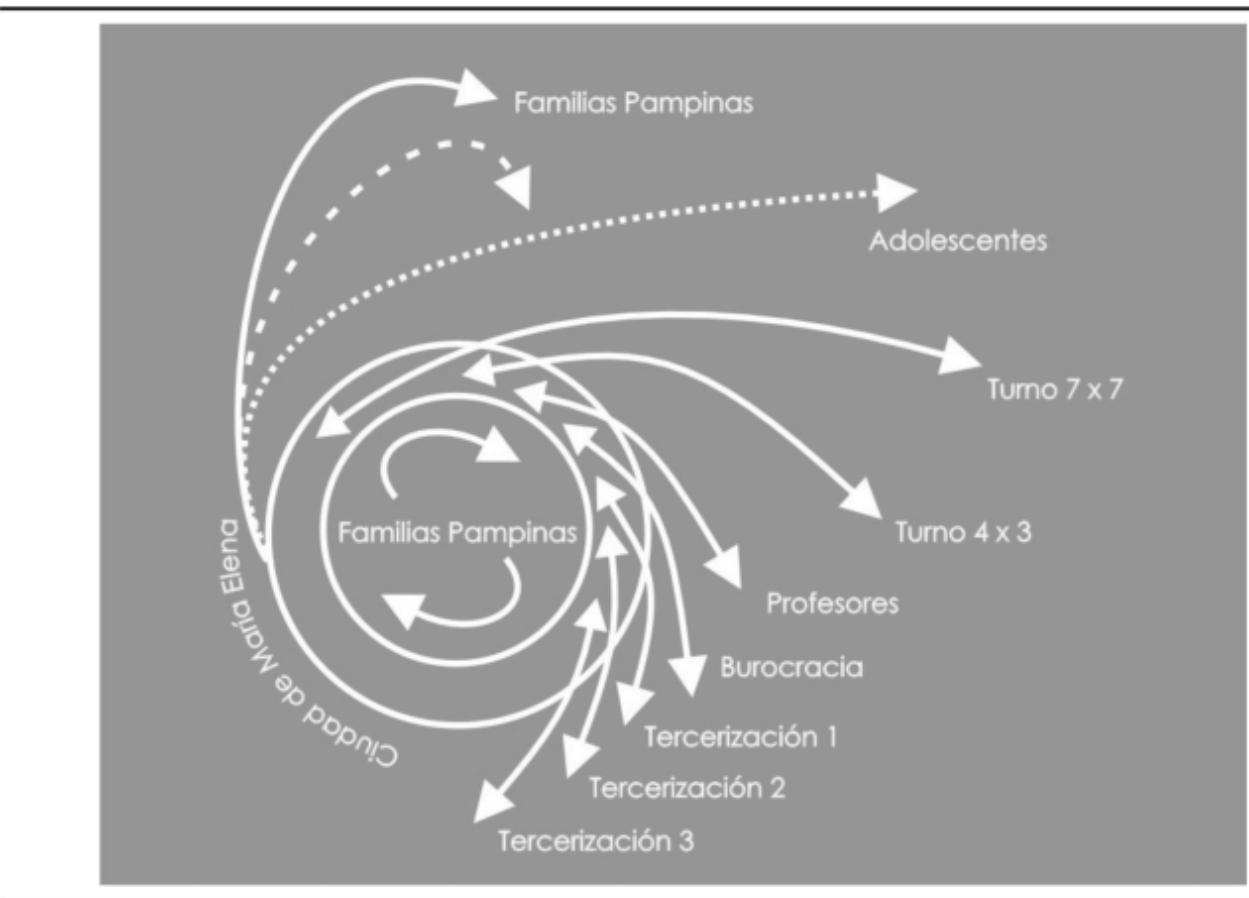

Fuente: Elaboración propia

En medio de este modelo laboral que es de reconversión (pleno empleo a subcontratación), puede observarse que es sólo en el centro donde habita o puede habitar la memoria de los hombres, mujeres, ancianos y familias pampinas que aún viven en María Elena. Estos son los últimos depositarios de la vida colectiva de la ciudad, "de la gran ciudad", la pampa y el mito del movimiento social; y, paradojalmente, son quienes se encuentran cada vez más al margen de la vida social y laboral. Solo ellos pueden defender o reivindicar una idea de ciudad. Pero, como sostiene Giddens: "este fenómeno sirve para abrir un abanico de posibilidades de cambio al liberar de las restricciones impuestas por hábitos y prácticas locales" (Giddens, 1994, p. 31), por lo que resulta coherente que la juventud exprese sin miramientos que "la vida está en otro lado", porque tienen el convencimiento que ME "no existirá en diez años más, ni ellos estarán ahí en cinco”.

Frente a lo señalado, también se debe hacer frente a un fenómeno de conmutación a la que se han referido Aroca y Atienza (2008), en la medida que los desplazamientos -producto de la flexibilización- indican que el trabajo tiende para muchos a ser sólo una referencia domiliciliar. Categóricamente, gran parte de los trabajadores no gastan nada de lo que reciben en $\mathrm{ME}$, sino en otras ciudades, e inclusive en otras regiones que es donde residen. No existe relación entre lugar de trabajo y lugar de consumo, lo que resta dinamismo al exiguo comercio local, 
afectando algunos tipos de empleo asociados al gasto y consumo diario (panaderías, pequeños almacenes) y los ingresos.

La ciudad y la idea de ciudad queda atrapada en ese centro, pero llena de mundos circundantes y de nuevas conexiones. Y los que se la han apropiado por décadas se quedan sin formas de protección, sin reconocimiento de las antiguas formas productivas de las que han formado parte, sin mito, sin ciudad, con un sentimiento vital y permanente de inseguridad, con una forma de enfrentar el trabajo que no permite la cohesión de la sociedad, y con una experimentación cotidiana de la violencia de la alteridad provocada por la ocupación de puestos de trabajo por personas no locales y con una marcada sensación de que hay un control absoluto de su subjetividad, lo que los deja sin posibilidad de respuesta política frente a los ingentes cambios.

Puesto en perspectiva lo anterior, nos indica que se alteran las funciones básicas de toda tradición: su carácter normativo, su condición legitimadora, identificativa y hermenéutica. Es decir, se transforma todo el background desde donde brota el sentido de las acciones y expresiones posibles que se han expresado espacialmente en la ciudad practicada. De este modo, la morada se convierte en un "hábitat móvil, como una forma de vivir el tiempo y el espacio no como si fueran estructuras fijas y cerradas, sino como fuentes que incitan a una apertura crítica”, en el que se juega el sentido de la identidad, del lugar y de la pertenencia” (Chambers, 1994, p. 18).

\section{Los últimos pampinos y el destino de la ciudad}

En esta "nueva ciudad”, los que se dicen y reconocen como "más pampinos" y "más eleninos" son hombres y mujeres refugio, relictus, memoria; únicos con capacidad de establecer relaciones cronotópicas y topofílicas. Dentro de la elongación deformadora de toda memoria inscriben eventos con referencias y marcadores espaciales y de redes afectivas y de relaciones que se convierten en huellas sobre la propia vida y el uso de los espacios (Hall, 1973; Sennett, 2001) y que confirman su mito en la hora de su declinación. Sólo que la fórmula no tiene auditorio para ser comunicada y compartida entre generaciones, por lo que la ciudad no tiene continuidad en su narrativa y no puede encontrarse la "comunidad imaginada" (Anderson, 2002) y la de los relatos. Como sostiene Renato Ortiz (2008, p. 18), "el mito sólo es durable en tanto existe un relativo consenso en torno a su veracidad”.

Así, se enfrenta un doble juego. Por una parte, entre los que se sienten "auténticos pampinos" y "citadinos", los más desfavorecidos con las transformaciones se ven conminados a exagerar la belleza de la ciudad en la que viven, ocultando - a pesar del empobrecimiento infraestructural- las carencias de la vida que llevan en ella; por otra parte, las facilidades para entrar a ME y salir hacia otros puntos, la TV abierta y digital, la telefonía y conexión a la red —entre otras causas-, estimulan una constante mirada hacia el exterior, especialmente entre los más jóvenes (véase Rodríguez, Miranda y Mandujano, 2007; Mandujano, 2007), por lo que así como localmente se encuentra "otra cultura" se sale al encuentro de otra. En términos de Georges Balandier: "el acontecimiento que los medios de masas procesan se convierte en la matriz en la que se labran los mitos del presente" (1994, p. 166). 
No pueden pensarse estos elementos que estimulan la mirada hacia el exterior como los verdaderamente estructurantes, pues sólo son los últimos que se acoplan a un proceso largo de transformaciones. Esto, debido a que la matriz productiva -en el curso de 80 años de historia del asentamiento urbano industrial- se va refinando de la mano del ingente desarrollo tecnológico, en la que ya el trabajo físico se constituye en un elemento absolutamente marginal y residual dentro del proceso; cuestión que implica demandas de personal calificado, que si no se encuentra disponible en la ciudad — que es lo más frecuente- ${ }^{9}$, es cubierto por hombres y mujeres provenientes de cualquier otro lugar del país, ligados a cualquier tradición laboral, cultural y experiencia de vida.

Así, analíticamente nos enfrentamos a una constatación fáctica en relación a la ciudad: una frontera debilitada respecto de su propio relato. Los alter egos que le daban sentido ya no están, y aparecen otros muchos, reales o virtuales, interiores y exteriores. Por tanto, la ciudad se remodela y se redescribe a sí misma, en la medida que los soportes tradicionales son inencontrables como puntos de encuentro. El lugar donde se constituyó la vida es transgredido por efectos de políticas de desarrollo de la Compañía SQM, ya que quienes toman decisiones que impactan sobre la ciudad y la vida cotidiana no están ligados territorialmente a esa memoria social, experiencia laboral, cultural y ambiental que tiene su origen en una company town. En esta multinacional, en relación a sus trabajadores, la ciudad y sus habitantes, hay al menos cinco cosas muy claras:

- Se invierte para ganar dinero y no hacer filantropía. En el actual modelo de acumulación, empresarialmente, para ser exitoso se debe ser competitivo, producir con calidad y responder a la globalización, y esto se encuentra al margen de la consideración de la existencia de la ciudad.

- Las decisiones las toman accionistas dispersos y ubicados en cualquier región del planeta, cuya condición los define el no tener ninguna atadura a la pampa, la historia social y a la ciudad.

- Quienes se ven mayormente afectados por las decisiones son trabajadores arraigados y con una baja calificación laboral, con una historia y memoria específica, que han realizado su vida ahí. Estos no pueden seguir a la empresa en sus movimientos, y son quienes deben reconfigurar sus vidas en función de las decisiones que se transparentan o de aquellas no comunicadas y que corresponden al universo de lo incierto (véase Bauman, 2006).

- Que son los hombres, mujeres, sindicatos y organizaciones ciudadanas, y no la empresa ni sus accionistas los llamados a defender memorias y tradiciones que se sientan amenazadas o la misma ciudad; $y$,

- ME debe ser representada como un lugar en una cadena de posiciones, y es sólo el lugar donde la información y las decisiones se concretan.

De este modo, la contradicción vital e histórica entre capital y trabajo se desplaza: pasa de lo estructural a lo contingente, de lo colectivo a lo individual, del sujeto histórico al sujeto

\footnotetext{
9 Se trata de un aspecto muy funcional, en la medida que dentro de la lógica de la Compañía SQM esta condición acerca el número de habitantes estables al número crítico para funcionar de manera eficiente como empresa.
} 
efímero, del sujeto arraigado al ocasional, del activo al inactivo desvinculado del devenir de sus compańeros y la ciudad. Esto, porque la precaria seguridad laboral y existencial, y la ausencia de certezas con la que se vive en una ciudad que cada día es menos ciudad, da cuenta del control del individuo a través de la inevitable obsolescencia de sus experticias y del análisis del tamańo de la plantilla de trabajadores, los que están permanentemente sometidos a prueba en sus compromisos con la Compañía. Por tanto, desaparece la ciudad como concepto ligado a la productividad, y es la figura de un campamento la que se impone.

El quiebre que significó la privatización de la Compañía para las familias en 1988, imposibilita el juego dialéctico entre individuo y ciudad, la posibilidad de encontrar sus marcas y rituales, y un profundo debilitamiento de los procesos de objetivación, legitimización e institucionalización que otorgan las claves de las certezas que configuraron el mundo compartido y coherente. El proceso de cambio y modernización escenifica la pérdida de una condición ontogénica, de un habitar que define un modo de ser, de una matriz temporal, de construcciones intersubjetivas, de una conexión con una historia de larga data, que revela formas de relaciones y comunicación que pudieron concretarse en una ciudad que en principio y durante largas décadas se pensó con un gran horizonte temporal y no tuvo fecha de cierre ni extinción, y que sus habitantes la vieron siempre como infinita e indestructible, aun con el paisaje desolador $y$ al que se encuentra asociada la ciudad en su exterior.

En las observaciones señaladas se puede apreciar lo que en definitiva constituye un lugar: una relación entre cooperación y conflicto como base de la vida en común, a la que concurren personas, empresas e instituciones (Santos 2000, p. 275). Ahora, se enfrenta un cambio acelerado en la manera de percibir y vivir lo que queda la ciudad por parte de quienes la habitan de manera estable o intermitente, asociado a los riesgos e impactos derivados del proyecto político económico, el know-how, la flexibilidad laboral, el aceleramiento tecnológico, la irrupción de los medios de comunicación como promotores de lo deseable y a lo que se puede acceder en términos de consumo. En sentido estricto, son elementos residuales que en su conjunto y en sus articulaciones hablan de un trabado y doloroso tránsito desde una ciudad a un campamento minero que desafecta a hombres y mujeres, y expulsa a una memoria forjada por más de 80 años en este espacio de contención y conectada con un siglo y medio de historia.

A partir de la eliminación de toda rigidez debemos hablar de una modernización que subvierte lo que antropológicamente llamaríamos la memoria (histórica) y el imaginario que ha dado identidad a los trabajadores del salitre y a la expresión local de la revolución industrial en nuestro país en su forma de company town. En sentido estricto, si entendemos que las actuales empresas no están para producir nitratos o cobre, sino para producir dinero, ser un trabajador dentro de los marcos de una ciudad salitrera en transición a campamento significa que todo trabajador es vulnerable en cuanto prescindible, que su trabajo es precario en la medida que debe enfrentarse a una estructura particular de opciones y oportunidades que no puede contener ni manejar (véase Rodríguez y Miranda, 2008). Esas opciones y oportunidades hablan de inseguridad y de la desestructuración de los elementos propios del tejido material y simbólico que fijaron las coordenadas de la vida social en una comunidad especializada, en la medida que coincidieron la ciudad industrial con la ciudad habitacional, la del trabajo y del consumo. 
La individualización constituye una auténtica revolución silenciosa, ya que se altera el tejido social que ofrece la mirada de conjunto sobre la vida y la ciudad, que es donde aparece la ciudad que se camina y la de los rituales. El trayecto de lo colectivo a lo individual constituye el cambio más importante en la transición y en decaimiento de la tradición y de la ciudad; pero, no lo es menos en cuanto la ciudad también deviene en ruina.

Teóricamente, y de una forma más general, Beck (2002, pp. 164-165) escenifica tres aspectos de este proceso que coinciden con lo descrito: a) la disolución (sin precedentes) de las formas sociales históricas y de los vínculos, en relación a la subsistencia, b) la perdida de las seguridades, en cuanto el "saber hacer", creencias y las normas que operan como orientadoras, y c) nuevas formas de cohesión social. Esto, según el autor, y en sentido estricto es lo que se puede observar como la constitución de un modelo productivo y de relaciones laborales a-histórico, es decir, abstracto, sin ligazón espacial, sin memoria. De modo preciso, Martín Pascual -citando un trabajo de Malva Espinoza- indica para reforzar estas ideas: que la matriz neoliberal ha significado "inestabilidad en el empleo y altas tasas de rotación, desempleo y precarización del mismo, desprotección legislativa de los trabajadores, segmentación y exclusión en la seguridad social, pérdida de derechos adquiridos y disminución de exigencias reivindicativas, debilitamiento del rol del Estado y fortalecimiento de la autonomía empresarial que define unilateralmente las condiciones de trabajo, de salarios y los márgenes de rentabilidad que quiere alcanzar" (Pascual, 2007, p. 9).

Estas cuestiones son las que afectan el aspecto central de la orientación de la vida elenina: la coincidencia o no entre el enclave productivo y el habitacional.

\section{A modo de cierre}

Sabemos que la vida cotidiana es el lugar desde donde por excelencia se puede pensar lo social. Entonces, es precisamente a partir de los colapsos o los eventos estresantes que alteran los subsistemas específicos, y las distintas fórmulas que configuran anillos de trabajadores inconexos, atomizados, diferenciados, segregados y sin vínculos primordiales con el paisaje pampino, que debemos entender que el proceso de metamorfosis de la ciudad utópica -en su concepción inicial- a un campamento corresponde a la expresión empírica del posicionamiento de la globalidad en la localidad o internacionalización del complejo urbano industrial. Se trata de aquello de un proceso que la excede, que la resiente y se hace sentir en el día a día. Hay un importante crecimiento de la subcontratación y las consultorías que antes se realizaban en forma interna por la compañía; nuevos sistemas de turnos, un cambio en la constitución de la plantilla de trabajadores a partir de la "tercerización", que es lo que permite un aceleramiento de los procesos productivos en tiempos que se licitan, y, también, para poder hacer frente a fenómenos recesivos o coyunturas internacionales. Así, ya no son los "stocks" los que aumentan y disminuyen (Iranzo y de Paula Leite, 2006) sino que "el factor trabajo es el mecanismo de ajuste de costos de las empresas" (Pascual, 2007, p. 13), esto es lo que establece la figura de los trabajadores que quedan desarticulados, separados y diferenciados en términos económicos, históricos y culturales, deformando la imagen de la ciudad y que anuncian la prescindencia de esta forma de asentamiento humano. 
Lo que alguna vez fue una ciudad que a partir de la implementación de tecnologías de identificación y pertenencia ancladas en soportes comunicacionales, fue conocida en sus señas y en sus códigos, se abre y se contrae simultáneamente, hasta reducirse a expresiones mínimas de lo que puede ser considerada una ciudad como lugar de intercambio material y simbólico. La forma de ser de sus antiguos habitantes se empieza a volver discontinua como la de aquellos que no pertenecen a la ciudad, los hogares se alzan como provisionales ya que no hay claves para pensar la reproducción social y generacional como proyecto con arraigo local, y constantemente se están sobrepasando los límites del pensamiento y la experiencia tradicionales. La ciudad que queda entre los habitantes de más edad es una detenida en el tiempo, la del mundo pre TV.

Se enfrentan fuerzas que no son locales en la definición de la ciudad. Los sistemas de turnos y la subcontratación son elementos propios de las llamadas empresas "modernas" y "eficientes", y que desean hacer buenos negocios. Por ello, no hay respuesta local ni institucionalidad para defenderse frente a los cambios; tampoco sociedad civil ni espacios visibles de ciudadanía, reconociendo que el sindicato -en su momento- fue estructurante no sólo en relación a cuestiones de orden laboral sino en la estructuración de la comunidad y el devenir de la misma en la medida que eran indisociables el destino de la Compañía y de la ciudad; o, si se quiere, del trabajo y del habitar. Así, la comunidad no puede defenderse a sí misma, si se aspira a mantener una cierta idea de lo que significa la última ciudad del salitre, la ciudad refugio de aquellos que desplazados tras cada uno de los cierres de las ciudades y campamentos ahí se cobijaron como parias errantes.

Los indicadores son al menos muy transparentes: a) existen pocos viejos y pocas familias antiguas, ya que lo que queda de ciudad es un lugar esencialmente para ir a trabajar y no para vivir, por lo que se encuentran pocos mantenedores de la memoria colectiva, b) cada vez más son los trabajadores externos que incorporan insumos culturales provenientes de distintas regiones, aunque mantengan una relación tangencial o atópica con lo que queda de ciudad, c) existe un importante aumento de la masculinidad, lo que provoca presión sobre la población femenina residente, la que oscila entre desconfianza y expectativa, d) hay un predominio de matrimonios híbridos, donde sólo uno de los cónyuges es de $\mathrm{ME}$, e) existen muchos matrimonios donde ninguno de los cónyuges es de ME, f) existe el índice más bajo a nivel regional de instituciones formales desde donde pueda ejercerse ciudadanía, por lo tanto no hay posibilidades de contención del proceso de transformación, g) se precipita una gran inestabilidad de la población a partir de la implementación de sistemas de turnos, por lo que el conocimiento entre los trabajadores es exiguo y marginal, remitiéndose sólo a los compańeros de turno con los que se viaja en bus o con los que se desayuna, almuerza y cena, h) una rotación permanente de trabajadores que habla de la flexibilidad numérica y funcional de la plantilla, i) una presión por parte de los más jóvenes a partir de la renovación de expectativas por estudiar para ser un profesional, lo que implica la salida de la ciudad y la ampliación de sus propios espejos y frente a los de sus padres, j) una importante preocupación familiar por adquirir una vivienda en otras ciudades y regiones, ya que lo que pareció óptimo en algún momento en que en Chile se construía muy poco, hoy sólo constituye una vivienda básica con los nuevos estándares habitacionales (Rodríguez, Miranda y Mandujano 2007; Mandujano 2007). Asimismo, se deprime el pequeńo comercio con la salida de familias de $\mathrm{ME}$, y con la alimentación a escala 
prevista para el eslabonamiento de los sistemas de turnos de los trabajadores de SQM y los de las empresas contratistas y de los all inclusive que predominan. "Hay menos dinero circulando", señalan los comerciantes, porque hay menos familias consumidoras.

Lo anterior, si se piensa como una disociación de un complejo de elementos estructurantes, apunta a un cierto cierre de la historia social del salitre y al fin de una experiencia y concepción urbana, como a un esfuerzo teórico y empírico de modelación de la vida y la convivencia. También, a un vaciamiento de la memoria a partir del cambio de los residentes de la ciudad, de usos restringidos de la misma, de una infraestructura pobre y poco atractiva para quien provenga de otros universos urbanos y de la configuración de los anillos de trabajadores que la circundan, impactan, se marginan y renuevan con las relaciones laborales y productivas que se imponen.

Las representaciones sociales siempre están encaminadas a reducir lo vago, a establecer la comunicación, a sortear las situaciones problemáticas, y a generar consenso; al parecer todo aquello que comienza a perderse en medio de lo incontrolable e incontenible, devenido de la posición de $\mathrm{ME}$ en la economía regional, nacional y mundial. En este sentido, un análisis de algunas de estas aspas que mueven los soportes tradicionales y reestructuran la población y la forma de verse de sí mismos, hablan de "desanclaje" (Giddens, 1994, p. 32).

La pérdida en sentido estricto de los elementos propios de la comunicación en los marcos de lo que fue una comunidad especializada, delata la formación de una nueva comunidad o de una acelerada transición a un campamento compuesta por trabajadores esencialmente nómadas. Así, "referirse a la historia, a la traducción o a la memoria, supone siempre hablar de lo incompleto, de lo que nunca puede descifrarse completamente" (Chambers, 1994, p. 17). Pero, la formación de estos anillos diferenciados y sin contactos ni interacciones entre trabajadores, de los márgenes y límites que se imponen, nos hablan también de la existencia de otros cuerpos, concepciones, mundos y proyectos personales, donde la vida efectiva está en otro lado.

La reconversión de la empresa del sistema estandarizado de plena ocupación a un sistema desestandarizado más flexible y de subempleo desestabiliza la memoria y el tejido social de la ciudad, reestructura el estilo de vida en términos simbólicos y materiales, precipita la individualidad, se pone de espalda a la vida pública, y da cuenta de un escenario en el que no hay ni puede haber compromisos de largo plazo con ella ni en ella, más allá del deseo de algunos habitantes de preterizar el futuro y el presente para que la ciudad vuelva a ser lo que alguna vez fue. Por ello, si no existe ya la comunidad de destino, la del proyecto vital y de largo plazo, nos atrevemos hablar de la "Nueva María Elena", la que corresponde a un campamento de trabajadores sin memoria colectiva.

\section{Referencias bibliográficas}

Anderson, B. (2002). Las comunidades imaginadas. México: Fondo de Cultura Económica. Aroca, P. \& Atienza, M. (2008). La conmutación regional en Chile y su impacto en la región de Antofagasta. EURE, 34, 102, 97-120. 
Balandier, B. (1994). El poder en escenas. Barcelona: Serie Studio.

Bauman, Z. (2004). La globalización. Consecuencias humanas. Buenos Aires: Fondo de Cultura Económica.

Beck, U. (1998). La sociedad del riesgo. Hacia una nueva modernidad. Buenos Aires: Paidós. Chambers, I. (1994). Migración, cultura, identidad. Buenos Aires: Amorrortu editores.

De Mattos, C. (2007). Presentación. EURE, 33, 99, 5-6.

Friedman, J. (1992). The past in the future: history and the politics of identity. American Anthropologist, 94, 4.

Garcés, E (2007). Las ciudades del Cobre. Santiago: Ediciones Universidad Católica de Chile, Facultad de Arquitectura, Diseño y Estudios Urbanos.

Garcés, E. (1999). Las ciudades del Salitre. Santiago: Editorial Orígenes.

Giddens, A. (1994). Las consecuencias de la modernidad. Madrid: Alianza.

González P, J. (1997). La cultura en el sistema Guggenheim. La oficina salitrera como instancia de sociabilidad. Revista de la Facultad de Ingeniería y Ciencias Geológicas, Universidad Católica del Norte, 13, 13.

González P, J. (2003). La pampa salitrera en Antofagasta. Auge y ocaso de una era histórica. La vida cotidiana durante los ciclos Shanks y Guggenheim en el desierto de Atacama. Antofagasta: Ediciones Proa.

González, M. S. (2006). El mundo de las casas de lata. La vida en la pampa salitrera. En R. Sagrado \& C. Gazmuri (Dirs.), Historia de la vida privada en Chile. El Chile moderno de 1840 a 1925 (Tomo II, pp. 187-213). Santiago: Taurus.

Hall, E. (1973). La dimensión oculta. Enfoque antropológico del uso del espacio. Madrid: Instituto de Estudios de Administración Local.

Heidegger, M. (2007). Filosofía, ciencia y técnica. Santiago: Editorial Universitaria.

Iranzo, C. \& De Paula Leite, M. (2006). La subcontratación laboral en América Latina. En E. de la Garza (Coord.), Teorías sociales y estudios del trabajo: nuevos enfoques (pp. 268- 288). España: Editorial Anthropos y Universidad Autónoma Metropolitana -IZ.

Linch, K. (2008). La imagen de la ciudad. Barcelona: Gustavo Gili.

Linhart, D. (2007). Ayer solidarios, ahora rivales. En Le Monde diplomatique, El trabajo (pp. 23-29). Santiago: Editorial Aún creemos en los sueńos.

Lucena, H. (2006). Las nuevas relaciones industriales. En E. de la Garza (Coord.), Teorías sociales y estudios del trabajo: nuevos enfoques (207-221). España: Editorial Anthropos y Universidad Autónoma Metropolitana-IZ.

Mandujano, F. (2007). El rol de la escuela en el último pueblo salitrero: estudio descriptivo y prospectivo de la educación en María Elena, región de Antofagasta. Tesis de Magistratura en Administración Educacional, Universidad de Playa Ancha, Valparaíso.

Ortiz, R. (2000). Modernidad y espacio. Benjamín en París. Colombia: Editorial Norma.

Pascual, M. (2007). Chile: ¿̨más cerca o más lejos del trabajo decente? En Le Monde Diplomatique, El trabajo (pp. 7-18). Santiago: Editorial Aún creemos en los sueños. 
Rodríguez J. \& Miranda, P. (2008). Tiempo industrial y tiempos sociales en María Elena, la última ciudad del salitre. Chungara. Revista de Antropología chilena, 40, 1.

Rodríguez J.; Miranda, P. \& Mandujano, F. (2007). Claves de lectura en la transformación de una ciudad industrial. El caso de la ciudad salitrera de María Elena. Actas del $6^{\circ}$ Congreso Chileno de Antropología, Valdivia, Chile.

Rodríguez, J. (2004). La reinvención del paraíso: sueño y olvido en los habitantes de los últimos pueblos salitreros del desierto de Atacama, Chile. En V Coloquio Paul Kirchoff, Desierto y fronteras. El norte de México y otros contextos culturales (pp. 123-152). México: Universidad Nacional Autónoma de México, Instituto de Investigaciones Antropológicas y Plaza y Valdez.

Santos, M. (2000). La naturaleza del espacio. Técnica y tiempo. Razón y emoción. Barcelona: Ariel.

Sennett, R. (2001). Vida urbana e identidad personal. Barcelona: Ediciones Península.

Sennett, R. (2002). Carne y piedra. El cuerpo y la ciudad en la sociedad occidental. Madrid: Alianza Editorial.

Zapata, F. (2002). Los mineros como actores sociales y políticos en Bolivia, Chile y Perú durante el siglo XX. Estudios Atacameños, 22, 91-103. 